\title{
Crack propagation in biodegraded wood
}

\author{
Thibaud SURINI $^{1 *}$, Myriam CHAPLAIN ${ }^{2}$, Patrick CASTERA ${ }^{1}$, Gérard VALENTIN $^{2}$ \\ ${ }^{1}$ INRA, Université Bordeaux 1, CNRS, UMR US2B, Bâtiment A11, 351, Cours de la Libération, 33405 Talence Cedex, France \\ ${ }^{2}$ Université Bordeaux 1, INRA, CNRS, UMR US2B, Bâtiment A11, 351, Cours de la Libération, 33405 Talence Cedex, France
}

(Received 1 July 2009; accepted 3 February 2010)

\author{
Keywords: \\ decay / \\ Douglas fir / \\ fracture / \\ maritime pine
}

\begin{abstract}
- Fungal attack in wood involves severe mechanical losses, even in the early stages, due to depolymerisation of polysaccharides. The safety of building components could therefore be affected. It is believed that fracture properties could be much more sensitive to decay than conventionally measured properties, such as weight loss.

- In this study, we propose the application of a fracture mechanics test, which measures the fracture toughness, $K_{I C}$, during the biodegradation process. Two softwoods commonly used in construction, maritime pine and Douglas fir, were inoculated with Poria placenta. Samples were removed twice a week to determine the evolution of the decrease in their mechanical properties.

- Toughness was initially greater for maritime pine, but a significant decrease of this property was observed during decay progression, while $K_{I C}$ remained more stable for Douglas fir. For maritime pine there was a loss of $52 \%$ of $K_{I C}$, after 6 weeks of degradation. This species appears to be less durable even with respect to weight loss, which is less sensitive to decay than toughness.

- This is a promising test for bio-damage quantification; however, due to the wood heterogeneity, measurement of the true impact of biodegradation is still difficult.
\end{abstract}

\section{INTRODUCTION}

When atmospheric conditions are favourable, commercial timber may be prone to fungal attack. In addition, a wood moisture content of $20 \%$ is usually enough to initiate decay (Clausen and Yang, 2007; Zabel and Morrell, 1992), which can have dramatic consequences. It is established that brownrot decays mainly depolymerise polysaccharide components in wood (hemicelluloses, cellulose) (Irbe et al., 2006; Ritschkoff, 1996), which play an important part in wood mechanical resistance (Winandy and Lebow, 2001). Indeed, the degradation of wood polysaccharides and lignin causes a decrease in mechanical resistance, which appears prior to weight loss (Clausen and Kartal, 2003; Przewloka, 2004; Winandy et al., 2000). Moreover, Humar et al. (2006) observed a decrease of modulus of elasticity $(M O E)$ of $7.4 \%$ without concomitant loss of mass. Cartwright et al. (1936) concluded that a mass loss of $8.5 \%$ of biodegraded ash was associated with a decrease of $15 \%$ in compression strength, $26 \%$ in bending strength (Modulus of rupture, $M O R$ ) and $90 \%$ in impact resistance. In general, the modulus of rupture is found to be more sensitive to decay than the modulus of elasticity $(M O E)$ in the early stages (Winandy et al., 2000) of wood decay.

These findings show the necessity of measuring wood decay at its early stage, by choosing a more sensitive criterion. In addition, the mechanical behaviour of biodegraded wood must

\footnotetext{
*Corresponding author: surini@us2b.pierroton.inra.fr
}

be understood in order to avoid problems that could appear in situ.

It is known that a 3-point bending test is not appropriate (Winandy and Morrell, 1993), because it does not always measure the true resistance of a wood sample at the biodegraded zone, due to the stress field not being homogeneous along the beam. By contrast, a compression test is sufficient to rapidly detect biodegradation (Gui et al., 1996). However, such a test remains global and is not always representative of a localized biodegradation process, especially in the early stages of the fungal attack.

We propose the application of fracture mechanics tests to measure the resistance of a small area, localized at the crack tip. From these tests, the critical stress intensity factor (or toughness) $K_{I C}$ can be determined. It characterizes the conditions of the unstable propagation of a sharp crack. The experimental determination of this parameter is relatively simple and will be described later. However, its correct determination requires sufficiently large dimensions of the test specimen to remain in the conditions of brittle fracture (Linear elastic fracture mechanics, LEFM) (Bažant and Planas, 1998). If the dimensions are too small, determination of more sophisticated parameters must be made (Morel et al., 2005; Stanzl-Tschegg et al., 1996). Fracture mechanics tests are currently used to characterize wood material: these involve a drying process of natural cracks in wood cell walls that can reduce fracture resistance (Stanzl-Tschegg et al., 1994). Similarly, heat treatments have some negative consequences on fracture toughness, as 


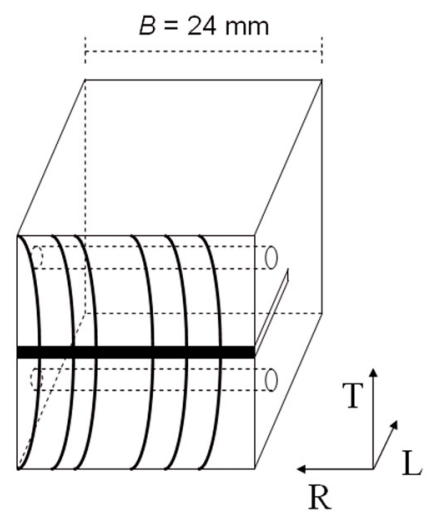

Figure 1. CT specimen: dimensions and design in TL configuration.

there is a loss of $35 \%$ of $K_{I C}$, after a treatment at $240{ }^{\circ} \mathrm{C}$ (Woessner, 2008). Reiterer and Sinn (2002) also reported a severe loss of fracture resistance after heat treatments, whatever the conditions.

As with heat treatment, biodegradation is responsible for the removal of some components of cell walls. It induces the development of clearly visible microcracks, and a decrease of rupture properties. Therefore, the aim of this study is to investigate the relevance of fracture mechanics tests to measure biodamage, and the evolution of toughness properties, according to the time of exposure to decay. As the biodegradation process is highly localized especially in its early stage, small dimensions specimens must be used. The dimensions chosen in the following discussion are slightly small for strict conditions of linear elastic fracture mechanics; however, it is assumed that small variations of toughness can be used to detect and follow biodegradation process.

\section{MATERIALS AND METHODS}

\subsection{Sampling}

Two softwood species that are currently used in the building sector in France were investigated. Only heartwood was studied, in order to be representative of timber that is used in wood building. For both species, only one beam, with dimensions $100 \times 100 \times 2000 \mathrm{~mm}(T \times$ $R \times L)$, was used to machine the specimens.

Maritime pine (Pinus pinaster Ait.) is a local species that grows in an area of 1 million hectares in the South-West of France. As a consequence, it is of high economical importance. The timber (approximately 30 years old) came from the Landes region and was purchased at the Lesbats sawmill, in Léon. According to the standard NF EN 350-1 (AFNOR, 1994), this species is moderately resistant to decay (class 3). Douglas fir (Pseudotsuga menziesii Mirb. (Franco)) is also moderately resistant to decay. It is widely found in French forests, as it is a fast growing species and provides timber with good properties. The timber, (approximately 30 years old) came from the Pomarède sawmill in the center of France.

Compact tension (CT) specimens (Fig. 1) were prepared according to the standard, ASTM-E399 (1990), with dimensions adapted

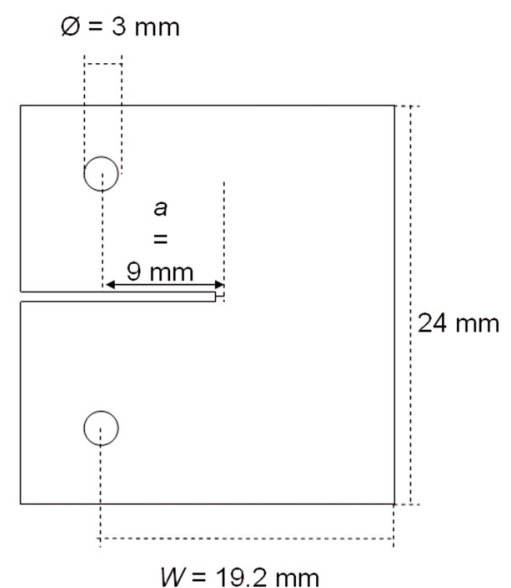

to the biodegradation tests, i.e. $24 \times 24 \times 24 \mathrm{~mm}$; a midline crack, defined by its length $a$ of $8 \mathrm{~mm}$, was sawn along the grain, and completed at the tip with a $1 \mathrm{~mm}$ crack using a razor blade (Fig. 1). Two $3 \mathrm{~mm}$ diameter holes were drilled on both sides of crack for the load application. Mechanical tests were applied in the tangential longitudinal (TL) plane. In wood, this plane is considered to be more representative of the material, because several rings are simultaneously fractured, representing an average of several years of growth.

For each species and each stage of degradation, 12 replicate samples were prepared from different parts of the same initial beam, in order to limit data variation (Tab. I). This sampling is assumed to limit the scattering of the initial properties of each sample allowing a better comparison at each stage of the period of the fungal attack. In addition, the initial density and the proportion of latewood were used as quantitative descriptors to verify the homogeneity of each sample before the fungal attack. After cutting, samples were conditioned in an oven, at $60^{\circ} \mathrm{C}$, to measure the initial dry mass $M i_{60}$. They were purposely not desiccated at $103{ }^{\circ} \mathrm{C}$ to avoid local deformation and microcracks due to high temperatures. Such a drying procedure would have diminished the natural mechanical resistance of the samples (Stanzl-Tschegg et al., 1994).

After biodegradation and rupture tests, a drying at $103{ }^{\circ} \mathrm{C}$ was applied in order to measure the final anhydrous mass $M f_{103}$, and calculate the initial anhydrous mass $M i_{103}$ (Eq. (1)), so that the true weight loss, $W L$, caused by decay, could be obtained (Eq. (2)),

$$
\begin{gathered}
M i_{103}=\frac{M i_{60}}{\left(1+H \%_{60}\right)} \\
W L=\frac{\left(M i_{103}-M f_{103}\right)}{M i_{103}} \times 100
\end{gathered}
$$

where $M i_{103}$ is the initial anhydrous mass at $103{ }^{\circ} \mathrm{C} ; M i_{60}$ is the initial mass after desiccation at $60^{\circ} \mathrm{C} ; \mathrm{H}_{60}$ is the moisture content of wood at $60{ }^{\circ} \mathrm{C} ; M f_{103}$ is the final anhydrous mass at $103{ }^{\circ} \mathrm{C}$.

\subsection{Proportion of latewood}

The proportion of latewood was measured for each specimen, since it is a descriptive variable of the macroscopic heterogeneity present at the site of the crack. For both species, this determination 
Table I. Sampling method for each species.

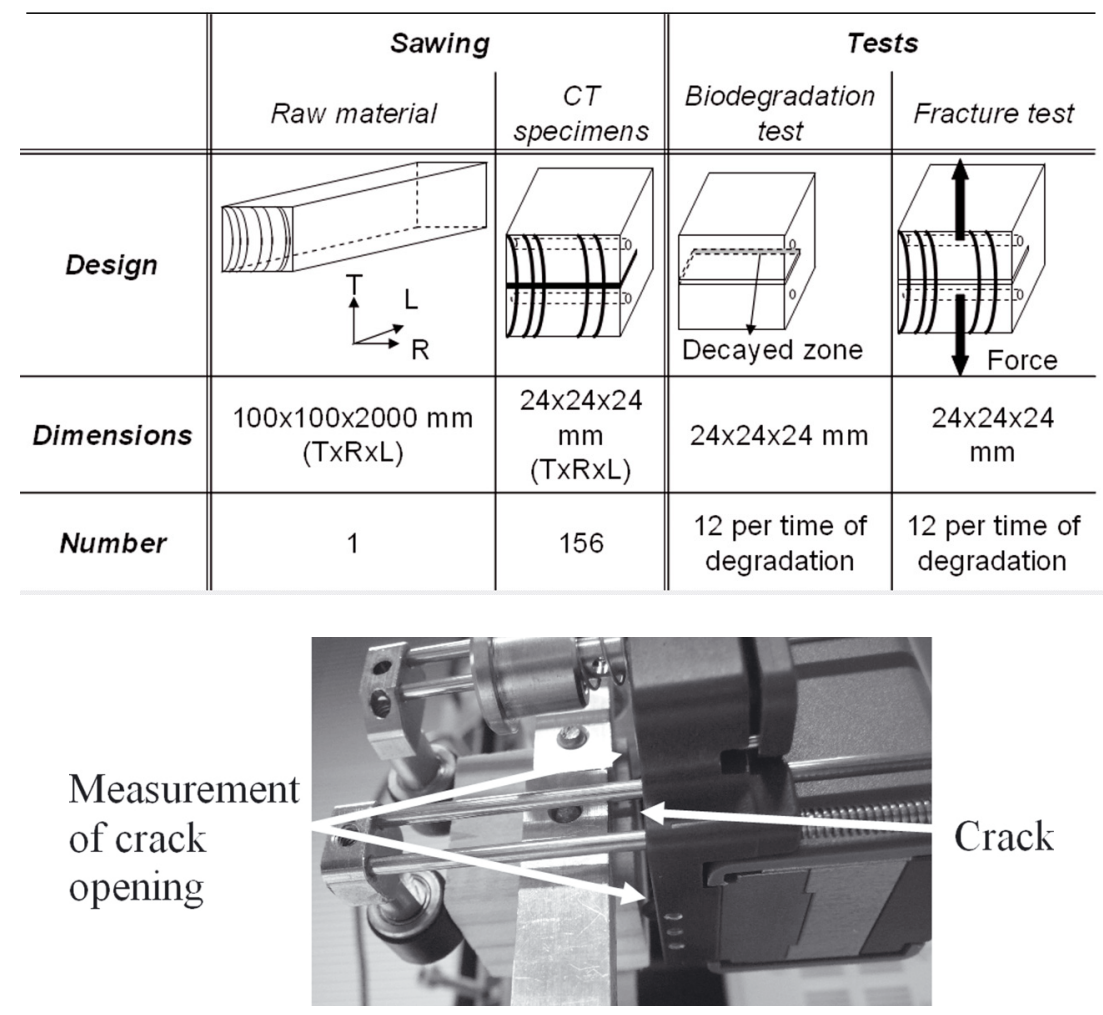

Figure 2. Measurement of crack opening.

was made easy by an abrupt and clearly visible colour transition between earlywood and latewood. This proportion is defined as the ratio between the total width of latewood, visible on the radial tangential (RT) plan of wood samples, and the total width of the specimen. This plan was scanned for each sample and the resulting images were zoomed and analysed using Labview ${ }^{\circledR}$ (National Instruments Corporation, Austin, Texas, USA) software. A line was drawn perpendicular to the rings, representing the position of the crack. On this line, the width of each latewood part was visually determined. Finally, in order to calculate the proportion of latewood, the sum of latewood parts was divided by the total number of pixels along this line (representing the total width of the sample).

\subsection{Biodegradation tests}

The brown-rot fungus, Poria placenta, was chosen to degrade samples. This was considered appropriate since brown rots, that attack hemicelluloses and cellulose, preferentially degrade softwoods and are consequently more virulent against these woods (Przewloka, 2004).

A malt-agar medium was prepared at a concentration of $45 \mathrm{~g} \mathrm{~L}^{-1}$ and sterilised for $25 \mathrm{~min}$ at $121^{\circ} \mathrm{C}$ in an autoclave, according to $\mathrm{NF}$ EN 113 (AFNOR, 1996). A $50 \mathrm{~mL}$ aliquot of medium was transferred to jars, before adding mycelium. After 2 weeks in a climatic chamber at $20{ }^{\circ} \mathrm{C}$ and $65 \%$ relative humidity, it covered the entire surface of the medium.

As a fracture test is localized, the degradation should preferentially occur at the site of testing. Thus, some mycelium was delicately laid at the bottom of the crack only, using a razor blade. Wood samples were then transferred to the malt-agar medium. A thin Parafilm band was wrapped around the sides of each sample to prevent fungus from developing on the entire wood surface such that only the crack tip could be attacked, i.e. the site submitted to the highest stresses at later in the testing process.

For each wood species, 12 specimens were removed twice a week for 6 weeks, representing 144 biodegraded specimens (plus 12 control undegraded specimens) for each species. After removal, specimens were sterilised by exposing to UV light and transferred to a climate controlled room with the same air conditions as described above, so that they reached a moisture content of $12 \%$.

\subsection{Fracture tests}

Before the fracture test, each specimen was weighed and dimensions were determined with a digital calliper, with an accuracy of $10^{-2} \mathrm{~mm}$. The depth of the initial crack was also measured. A Zwick/Roell (Zwick GmbH \& Co., Ulm, Germany) machine delivering a maximal force of $500 \mathrm{~N}$ was used to exert tension, i.e. mode I of fracture (opening mode). The displacement was regulated at $0.5 \mathrm{~mm} \mathrm{~min}^{-1}$ resulting in rupture in less than $3 \mathrm{~min}$. This duration is commonly used to avoid viscoelastic effects in mechanical tests on wood.

An extensometer was also placed on the specimen in order to measure the crack opening during the test (Fig. 2). For simplicity, the critical load, $F_{c}$, was taken to be the maximum from the load 
displacement curve obtained for each sample. The critical stress intensity factor, $K_{I C}$ (expressed as $\mathrm{MPa} \mathrm{m}^{1 / 2}$ ), was calculated using equation (3) (ASTM-E399, 1990):

$$
K_{I C}=\frac{F_{c}}{B \sqrt{W}} \times f\left(\frac{a}{W}\right)
$$

with

$$
f\left(\frac{a}{W}\right)=\frac{\left(2+\frac{a}{W}\right)\left(0.886+4.64 \frac{a}{W}-13.32\left(\frac{a}{W}\right)^{2}+14.72\left(\frac{a}{W}\right)^{3}-5.6\left(\frac{a}{W}\right)^{4}\right)}{\left(1-\frac{a}{W}\right)^{3 / 2}}
$$

$B$ and $W$ are the thickness and length of the specimen, respectively; whereas $a$ is the initial distance of the end of the crack from the load application holes, as shown by Figure 1 .

\subsection{Statistical analysis}

Analysis of variance ANOVA with the risk $\alpha=5 \%$ was performed using Minitab v. $15^{\circledR}$ (Minitab Inc., State College, Pennsylvania, USA) software, in order to compare mean values. In addition, a principal component analysis (PCA) was carried out. A PCA enables visually discrimination of individuals (or samples) in a multidimensional space in which the new axes (principal components) are the eigenvectors of the covariance matrix of the initial variables. They are therefore independent of each other. The projection of variables in the plane is represented by vectors with sizes that are proportional to their contribution to this plane. The angle of a variable vector with an axis is proportional to the correlation of the variable with the corresponding component. Such a representation allows the analysis of samples with a complex correlation structure. Statistically a PCA is significant if the first two components represent more than $50 \%$ of the overall variability, and the first three around $80 \%$ of the variability.

\section{RESULTS}

With maritime pine, the density was statistically equivalent, regardless of the sample tested $(p=0.62)$. With Douglas fir, control samples were initially heavier than biodegraded samples, but still were statistically equivalent. The statistical homogeneity for each species at the $95 \%$ confidence interval level is presented in Figure 3. We conclude from these results that the evolution of mechanical properties with the progression of decay can be analysed without any significant bias due to material variability.

In order to facilitate the analysis of results and avoid scattering of data, a principal component analysis (PCA) was performed for all measured variables: fracture toughness, density, weight loss, degradation time, and latewood \%. PCA takes the eigenvectors of the covariance matrix for these five variables, and provides five principal components that are independent. Figure 4 presents the results obtained in the 1,2 plane (approximately $80 \%$ of the overall variability, $53.7 \%$ for the first component only). The projection of data in the 1,2 plane (Fig. 4) showed, firstly, that Douglas fir and maritime pine were clearly separated by the proportion of latewood, with mean values of $40 \%$ and $34 \%$, respectively. Secondly, the closer position of maritime pine data with respect to the variables indicated that this species had a greater toughness, but also a higher weight (a)

Alpha $=0.05$

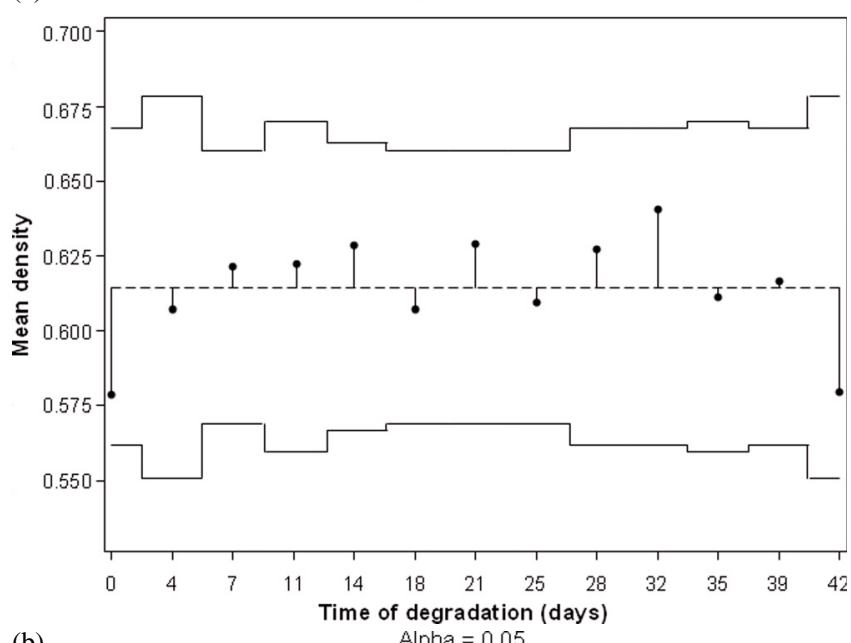

(b)

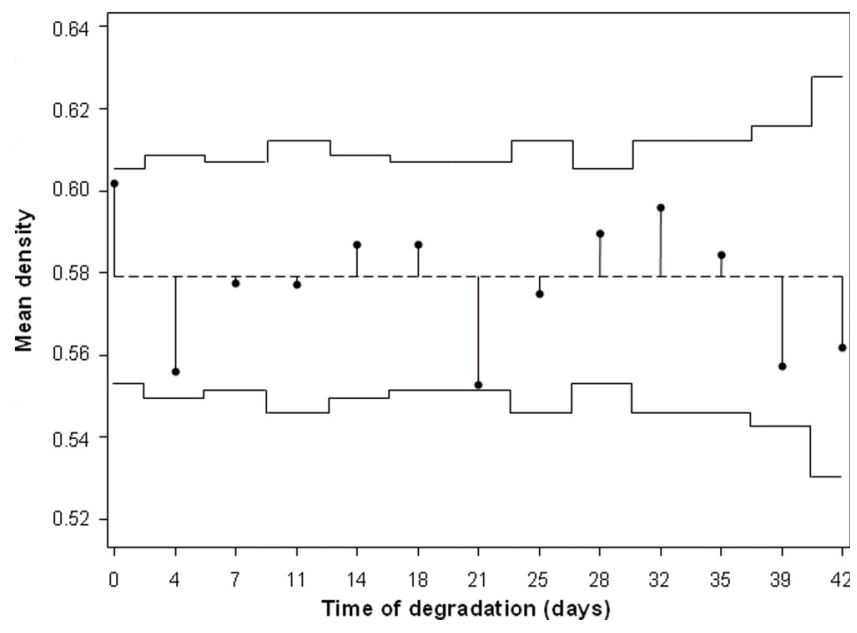

Figure 3. Statistical comparison of the mean initial density of samples (the dotted line represents the global mean; continuous lines represent the number of samples and circles represent mean values for each level of comparison. Mean values that are between continuous lines are equivalent); (a) for maritime pine; (b) for Douglas fir.

loss. Besides, the sensitivity to decay of pine was confirmed by a larger variation of these data according to time of degradation (the progression of decay is indicated by dotted lines and arrows). Finally, the negative correlation between toughness, density and degradation time indicated a strong reduction of toughness with decay.

Table II presents the statistical results (mean \pm SD) for all variables during the 6 weeks of biodegradation. It should be noted that the fracture toughness of both undegraded materials are in agreement with literature values (Boatright and Garrett, 1983; Schniewind and Centeno, 1973). Indeed, the initial value of toughness was 38\% higher for pine than for Douglas fir; whereas density was marginally lower for the pine samples. After degradation, the lower durability of pine compared to Douglas fir was confirmed. Measurements of weight loss were used to evaluate this observation further. For each period of degradation, mass loss was lower for Douglas fir than for pine. 


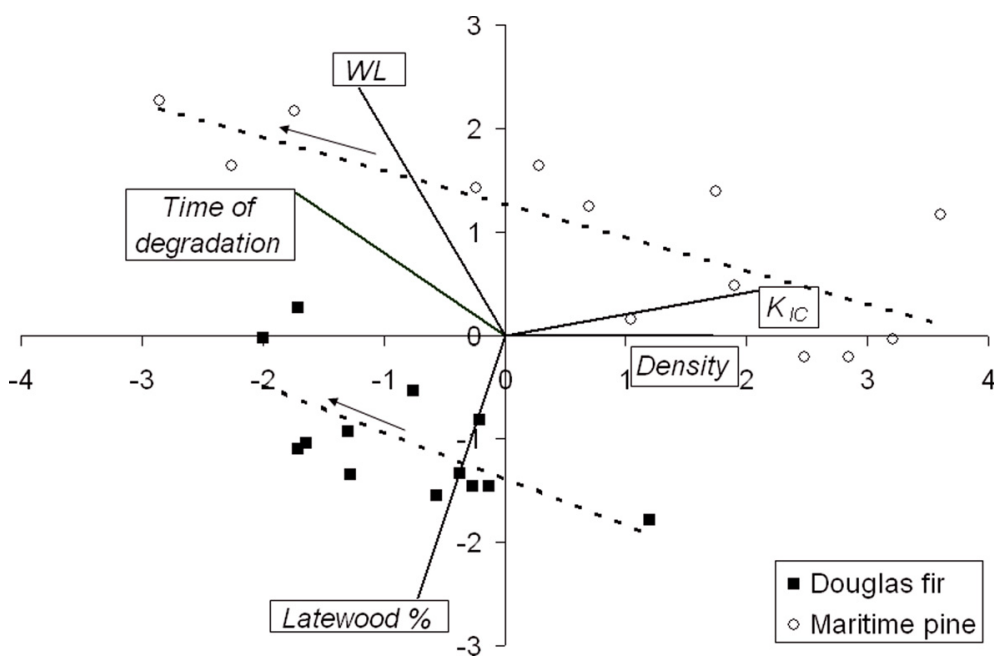

Figure 4. Principal component analysis of all measured variables (each point is the mean value of 12 replicates); solid lines indicate the weight of each variable in the normalised 1,2 plane. Dotted lines and arrows indicate the trends of decay progression for both species.

Table II. Statistical values of properties (density, latewood \%, weight loss and $K_{I C}$ ) after degradation, according to its duration.

\begin{tabular}{|c|c|c|c|c|c|c|c|c|c|c|c|c|c|c|c|c|c|c|}
\hline \multirow{3}{*}{$\begin{array}{l}\text { Time of } \\
\text { degradation } \\
\text { (days) }\end{array}$} & \multicolumn{9}{|c|}{ Douglas fir } & \multicolumn{9}{|c|}{ Maritime pine } \\
\hline & \multicolumn{2}{|c|}{ Density } & \multicolumn{2}{|c|}{$\begin{array}{c}\text { Latewood } \\
(\%)\end{array}$} & \multicolumn{2}{|c|}{$\begin{array}{l}\text { Weight } \\
\text { loss (\%) }\end{array}$} & \multicolumn{3}{|c|}{$\mathrm{K}_{\mathrm{IC}}\left(\mathrm{MPa} \cdot \mathrm{m}^{1 / 2}\right)$} & \multicolumn{2}{|c|}{ Density } & \multicolumn{2}{|c|}{$\begin{array}{c}\text { Latewood } \\
(\%) \\
\end{array}$} & \multicolumn{2}{|c|}{$\begin{array}{l}\text { Weight } \\
\text { loss }(\%)\end{array}$} & \multicolumn{3}{|c|}{$\mathrm{K}_{\mathrm{IC}}\left(\mathrm{MPa} \cdot \mathrm{m}^{1 / 2}\right)$} \\
\hline & Mean & $\mathrm{SD}$ & Mean & $\mathrm{SD}$ & Mean & SD & Mean & SD & $\begin{array}{c}\text { Toughness } \\
\text { loss }(\%)\end{array}$ & Mean & SD & Mean & $\mathrm{SD}$ & Mean & $\mathrm{SD}$ & Mean & SD & $\begin{array}{c}\text { Toughness } \\
\text { loss }(\%)\end{array}$ \\
\hline$\overline{0}$ & 0.60 & 0.034 & 41.6 & 5.70 & 0 & 0 & 0.28 & 0.031 & 0 & 0.58 & 0.031 & 29.0 & 6.67 & 0 & 0 & 0.42 & 0.071 & 0 \\
\hline 4 & 0.56 & 0.029 & 33.9 & 5.26 & 0.49 & 0.15 & 0.23 & 0.031 & 18 & 0.61 & 0.027 & 37.1 & 6.27 & 0.43 & 0.14 & 0.42 & 0.053 & 0 \\
\hline 7 & 0.57 & 0.017 & 38.7 & 4.46 & 0.22 & 0.084 & 0.20 & 0.046 & 29 & 0.62 & 0.048 & 37.6 & 5.14 & 0.85 & 0.78 & 0.34 & 0.048 & 19 \\
\hline 11 & 0.58 & 0.036 & 39.5 & 7.01 & 0.43 & 0.38 & 0.24 & 0.038 & 14 & 0.63 & 0.042 & 39.2 & 7.05 & 0.74 & 0.67 & 0.37 & 0.051 & 12 \\
\hline 14 & 0.58 & 0.033 & 42.1 & 5.21 & 0.64 & 0.59 & 0.22 & 0.042 & 21 & 0.62 & 0.066 & 34.4 & 9.54 & 1.95 & 0.81 & 0.31 & 0.066 & 26 \\
\hline 18 & 0.59 & 0.033 & 41.5 & 7.45 & 0.95 & 0.70 & 0.24 & 0.041 & 14 & 0.60 & 0.060 & 29.2 & 7.39 & 2.06 & 1.03 & 0.32 & 0.10 & 24 \\
\hline 21 & 0.55 & 0.26 & 37.7 & 9.48 & 1.21 & 0.96 & 0.25 & 0.048 & 11 & 0.62 & 0.082 & 37.0 & 9.70 & 2.40 & 1.31 & 0.28 & 0.057 & 33 \\
\hline 25 & 0.56 & 0.042 & 41.9 & 9.78 & 2.61 & 1.94 & 0.20 & 0.052 & 29 & 0.60 & 0.057 & 32.5 & 7.03 & 3.78 & 2.05 & 0.30 & 0.072 & 29 \\
\hline 28 & 0.58 & 0.031 & 44.0 & 5.57 & 2.00 & 1.51 & 0.21 & 0.034 & 25 & 0.60 & 0.074 & 33.5 & 6.55 & 6.32 & 4.00 & 0.25 & 0.11 & 40 \\
\hline 32 & 0.58 & 0.050 & 43.4 & 8.57 & 2.73 & 2.56 & 0.22 & 0.034 & 21 & 0.62 & 0.095 & 32.8 & 10.7 & 5.83 & 2.82 & 0.27 & 0.082 & 36 \\
\hline 35 & 0.57 & 0.029 & 44.8 & 9.98 & 2.81 & 2.62 & 0.22 & 0.049 & 21 & 0.56 & 0.071 & 35.5 & 9.12 & 9.63 & 4.48 & 0.18 & 0.080 & 57 \\
\hline 39 & 0.54 & 0.023 & 37.9 & 3.64 & 2.67 & 2.29 & 0.22 & 0.032 & 21 & 0.57 & 0.076 & 33.5 & 5.56 & 9.50 & 5.62 & 0.21 & 0.083 & 50 \\
\hline 42 & 0.55 & 0.027 & 35.4 & 5.20 & 2.30 & 1.76 & 0.24 & 0.041 & 14 & 0.53 & 0.041 & 34.7 & 9.73 & 10.85 & 3.02 & 0.20 & 0.059 & 52 \\
\hline
\end{tabular}

For both species, the general trend can be characterized by a simple quadratic fitting, indicating a slow variation at the beginning of the fungal attack (Fig. 5). By contrast, the measurements of toughness revealed a linear fit, as shown by Figures $6 \mathrm{a}$ and $6 \mathrm{~b}$. This trend, mainly visible with the pine samples, shows a higher sensitivity to measured toughness compared to weight loss, especially at the early stages of degradation. Moreover, a correlation between the duration of degradation and $K_{I C}$ was tested. The degradation was more rapid with pine (Pearson's coefficient $=-0.66)$ than with Douglas fir (Pearson's coefficient $=-0.25$ ). The effect of biodegradation was not as clear at the early stages for Douglas fir, even with respect to toughness, $K_{I C}$.

As Douglas fir was not as degraded as pine the results of weight loss were somewhat hidden by the dispersion of the data. It was also observed that toughness exhibited a small de- crease over time of degradation (Fig. 6b). However, toughness values were statistically equivalent $(p=0.23)$, whatever the degradation, showing that there were no significant decrease in this parameter.

The coefficient of variation $(\mathrm{COV})$ calculated from the standard deviation revealed a high variability of the mechanical property (typically $\mathrm{COV}$ exceeds 20 ), which is characteristic of most strength properties in wood. However, this $\mathrm{COV}$ was found to be much higher for weight loss, in excess of 50\% in the majority of cases. It shows that mass loss is not a sufficiently reliable criterion.

\section{DISCUSSION}

We have compared two wood species and found in this study maritime pine to be initially more resistant to crack 
(a)

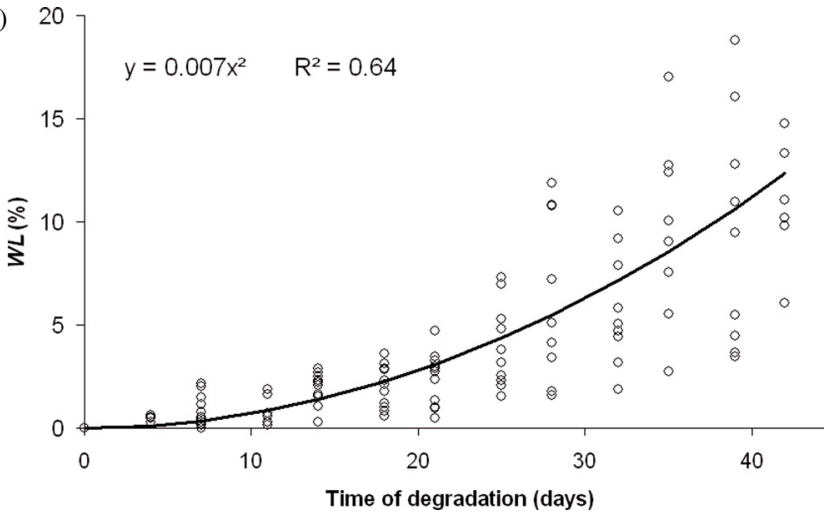

(b)

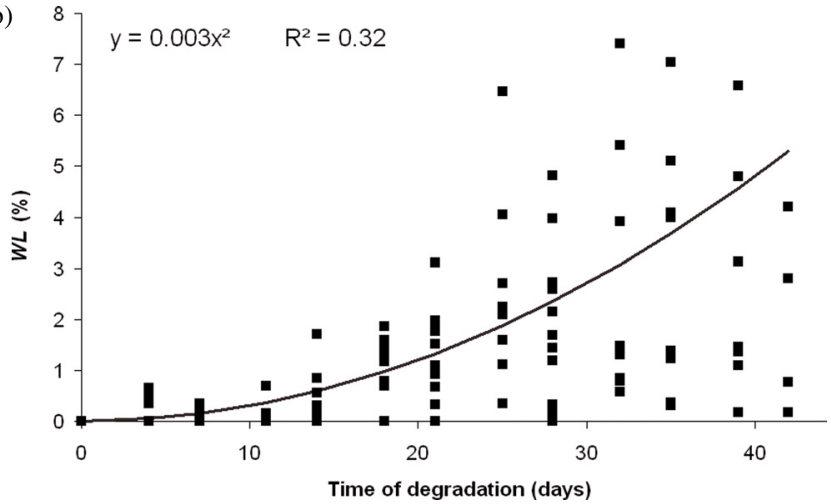

Figure 5. Relationship between weight loss and time of degradation; (a) for maritime pine; (b) for Douglas fir.

initiation than Douglas fir, despite its marginally lower density. Taking into account that other mechanical properties of maritime pine are generally also high $(M O E=11300 \mathrm{MPa}$; $M O R=95 \mathrm{MPa})($ Nepveu, 1994), the use of this species for structural applications is appropriate. This is similar to the common use of Douglas fir. One possible reason for the lower fracture toughness of Douglas fir is the strong heterogeneity between earlywood and latewood in this species (density ratio may reach a value of 3 ), which could be responsible for a non-homogeneous stress state along the crack tip, and possibly higher stress concentration. One disadvantage of the use of maritime pine is its variability in wood properties (Tab. II). This variability has been studied previously (Castéra et al., 1999; Knapic and Pereira, 2005; Machado and Cruz, 2005; Pot et al., 2002) but still needs to be taken into account when designing protocols. In addition, the heterogeneity of wood is responsible for a large variability of toughness. Since fracture tests are destructive, it is difficult to measure the real impact of decay, because the configuration of wood samples (density, growth rings, etc.) can also affect the results.

Despite the drawback of inherent variability, this study reveals a greater sensitivity of toughness measurements over the course of degradation for maritime pine, in comparison with mass loss. Although the variability of samples was minimised by using specimens from the same piece of wood, weight losses were too heterogeneous to draw any conclusions from this data. This may be due to the small size of specimens sub-
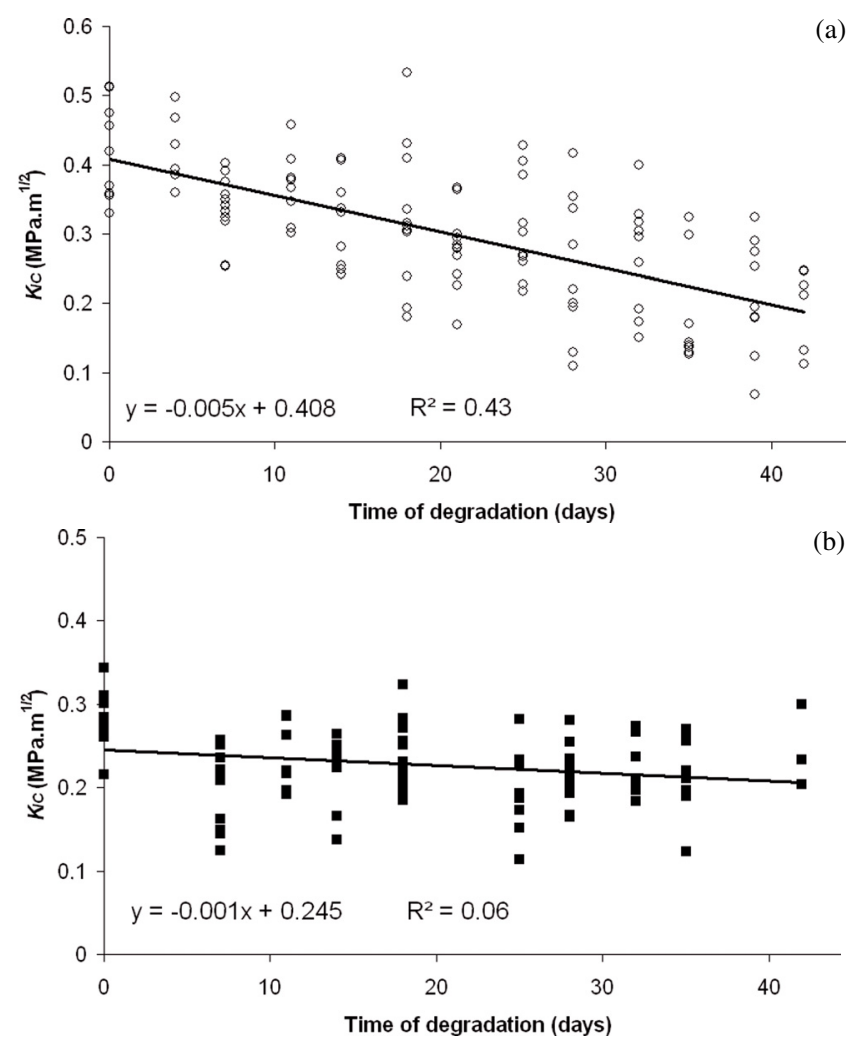

Figure 6. Relationship between $K_{I C}$ and time of degradation; (a) for maritime pine; (b) for Douglas fir.

jected to biodegradation tests. The use of fracture mechanics allows the variation of results to be minimised, which is more representative of the true effects of biodegradation. Additionally, in the early stages of degradation, the evolution of $K_{I C}$ is more sensitive than weight loss (Tab. II), proving the value of using fracture mechanics in early detection of decay.

By contrast, it appears that maritime pine is more sensitive to biodegradation than Douglas fir. Whatever the extent of degradation, the loss of mechanical toughness remains below $30 \%$ for Douglas fir, whereas it reaches $52 \%$ at the end of the test for maritime pine. Furthermore, for pine, the longer the degradation period the higher the decrease of $K_{I C}$, the correlation of which appears to be linear. Finally, its mass loss continued to increase with time, indicating a higher sensitivity to decay.

Although these two species belong to the same class of natural durability (class 3 ), there could be an effect of the proportion of latewood, in addition to chemical differences. Indeed, measurements revealed that Douglas fir samples had thicker rings and a higher ratio of latewood than maritime pine samples. As latewood is denser than earlywood due to the thicker cell walls (Donaldson, 1992; Plomion et al., 2001), it can slow down the progression of decay. The state of degradation is consequently less easily determined.

Fracture tests have some drawbacks, because they are difficult to undertake and destructive. But, although these tests were not so relevant with Douglas fir, which was here found 
more durable than pine, they are still more precise and variations of toughness appear earlier than weight loss, whatever the species. After 6 weeks, the mechanical degradation is not clear enough to be detected on Douglas fir, whereas chemical phenomena may have occurred even earlier than mechanical ones (Clausen and Kartal, 2003). But a longer period of degradation may have justified the utilisation of a fracture test. Indeed, for maritime pine that was more sensitive to decay, it appears in these conditions that fracture mechanical tests can be used in early detection. Besides, these tests also bring some useful information on crack resistance of wood, that could allow to predict the effect of biodegradation on the long-term resistance of structural pieces.

\section{CONCLUSION}

After a biodegradation process using $P$. placenta, the toughness of maritime pine measurably decreased, even at early degradation, and was more obvious than mass loss. These findings confirm that mechanical consequences of rots are more severe and predictive than weight loss, which is commonly used to determine biodegradation. Douglas fir exhibited lower initial fracture toughness than maritime pine but had a greater stability of this property against decay. These results provide a basis for further work to calibrate biodegradation damage models of wood, but a greater amount of tests and, if possible, tests on larger specimens will be necessary.

Acknowledgements: The authors wish to thank Mrs Christine Délisée and Mr. Jerôme Malvestio for their help and Mrs Nicola Hewitt for the revision of English. They are also very grateful to $\mathrm{Mr}$. Xavier Basile and the company Zwick/Roell.

\section{REFERENCES}

AFNOR, 1994. NF EN 350-1, Durabilité du bois et des matériaux dérivés du bois - Durabilité naturelle du bois massif - Partie 1: Guide des principes d'essai et de classification de la durabilité naturelle du bois. Association Française de Normalisation, La Plaine Saint-Denis, 20 p.

AFNOR, 1996. NF EN 113, Produits de préservation du bois Méthode d'essai pour déterminer l'efficacité protectrice vis-à-vis des champignons basidiomycètes lignivores - Détermination du seuil d'efficacité. Association Française de Normalisation, La Plaine Saint-Denis, $32 \mathrm{p}$.

ASTM-E399, 1990. Standard test method for plane-stain fracture toughness of metallic materials. ASTM International, West Conshohocken, PA, $33 \mathrm{p}$.

Bažant Z.P. and Planas J., 1998. Fracture and size effect in concrete and other quasibrittle materials, CRC Press, Boca Raton, Florida, 640 p.

Boatright S.W.J. and Garrett G.G., 1983. The effect of microstructure and stress state on the fracture behaviour of wood. J. Mater. Sci. 18: 2181-2199.

Cartwright K.S.G., Campbell W.G., and Armstrong F.H., 1936. The influence of fungal decay on the properties of timber. I. The effect of progressive decay by Polyporus hispidus, Fr., on the strength of english ash (Fraxinus excelsior, L.). Biol. Sci. 120: 76-95.

Castéra P., Nepveu G., and Chantre G., 1999. Principaux facteurs de contrôle de la variabilité du bois chez le pin maritime (Pinus pinaster Ait.). In: $5^{\mathrm{e}}$ colloque ARBORA : Propriétés et usages du pin maritime, ARBORA, Bordeaux, pp. 91-101.
Clausen C.A. and Kartal S.N., 2003. Accelerated detection of brown-rot decay: Comparison of soil block test, chemical analysis, mechanical properties, and immunodetection. For. Prod. J. 53: 90-94.

Clausen C.A. and Yang V., 2007. Protecting wood from mould, decay, and termites with multi-component biocide systems. Int. Biodeter. Biodegr. 59: 20-24.

Donaldson L.A., 1992. Lignin distribution during latewood formation in Pinus radiata D. Don. IAWA Bull. 13: 381-387.

Gui Y.Q., Nicholas D.D., and Crawford D., 1996. A miniature mechanical apparatus and test protocol for bending and crushing tests in wood preservation research. For. Prod. J. 46: 77-80.

Humar M., Bucar B., and Pohleven F., 2006. Brown-rot decay of copperimpregnated wood. Int. Biodeter. Biodegr. 58: 9-14.

Irbe I., Andersons B., Chirkova J., Kallavus U., Andersone I., and Faix O., 2006. On the changes of pinewood (Pinus sylvestris L.) Chemical composition and ultrastructure during the attack by brown-rot fungi Poria placenta and Coniophora puteana. Int. Biodeter. Biodegr. 57: 99-106.

Knapic S. and Pereira H., 2005. Within-tree variation of heartwood and ring width in maritime pine (Pinus pinaster Ait.). For. Ecol. Manage. 210: 81-89.

Machado J.S. and Cruz H.P., 2005. Within stem variation of maritime pine timber mechanical properties. Holz Roh Werkst. 63: 154-159.

Morel S., Dourado N., Valentin G., and Morais J., 2005. Wood: a quasi brittle material, R-curve behavior and peak load evaluation. Int. J. Fract. 131: 385-400.

Nepveu G., 1994. Variabilité. In: Jodin P. (Ed.), Le Bois, Matériau d'Ingénierie, ARBOLOR, Nancy, pp. 127-182.

Plomion C., Leprovost G., and Stokes A., 2001. Wood formation in trees. Plant Physiol. 127: 1513-1523.

Pot D., Chantre G., Rozenberg P., Rodrigues J.C., Jones G.L., Pereira H., Hannrup B., Cahalan C., and Plomion C., 2002. Genetic control of pulp and timber properties in maritime pine (Pinus pinaster Ait.). Ann. For. Sci. 59: 563-575.

Przewloka S.R., 2004. Comparison of rapid decay testing methodologies for the screening of new wood preservatives. PG04-5015, Forest and Wood Products Research and Development Corporation, Denis M Cullity Research Fellowship Report, 88 p.

Reiterer A. and Sinn G., 2002. Fracture behaviour of modified spruce wood: a study using linear and non linear fracture mechanics. Holzforschung 56: 191-198.

Ritschkoff A.-C., 1996. Decay mechanisms of brown-rot fungi. VTT Publications No. 268, Technical Research Centre of Finland, Espoo, $105 \mathrm{p}$.

Schniewind A.P. and Centeno J.C., 1973. Fracture toughness and duration of load factor I. Wood Fiber Sci. 5: 152-159.

Stanzl-Tschegg S.E., Tschegg E.K., and Teischinger A., 1994. Fracture energy of spruce wood after different drying procedures. Wood Fiber Sci. 26: 467-478.

Stanzl-Tschegg S.E., Tan D.M., and Tschegg E.K., 1996. Fracture resistance to the crack propagation in wood. Int. J. Fract. 75: 347-356.

Winandy J.E. and Morrell J.J., 1993. Relationship between incipient decay, strength, and chemical composition of Douglas-fir heartwood. Wood Fiber Sci. 25: 278-288.

Winandy J.E., Clausen C.A., and Curling S.F., 2000. Predicting the effects of decay on wood properties and modeling residual service-life. In: Proc. 2nd annual conference on durability and disaster mitigation in wood-frame housing, Forest Products Society, Madison, WI, pp. 261-263.

Winandy J.E. and Lebow P., 2001. Modeling Strength Loss in Wood by Chemical Composition. Part I. an Individual Component Model for Southern Pine. Wood Fiber Sci. 33: 239-254.

Woessner P., 2008. Influence d'un traitement thermique sur la résistance mécanique du bois de pin. M.S. thesis, Université Bordeaux 1, Bordeaux, $126 \mathrm{p}$.

Zabel R.A. and Morrell J.J., 1992. Wood microbiology. Decay and its prevention, San Diego, New York, 476 p. 